\title{
Single and multiple dose pharmacokinetics of maritime pine bark extract (Pycnogenol) after oral administration to healthy volunteers
}

\author{
Tanja Grimm¹, Roswitha Skrabala1 , Zuzana Chovanová2, Jana Muchová2 \\ Katarína Sumegová2 ${ }^{2}$ Anna Liptáková ${ }^{2}$ Zdeňka Ďuračková and \\ Petra Högger*1
}

Address: ${ }^{1}$ Institut für Pharmazie und Lebensmittelchemie, Bayerische Julius-Maximilians-Universität, Würzburg, Germany and ${ }^{2}$ Department of Medical Chemistry, Biochemistry and Clinical Biochemistry, Comenius University, Faculty of Medicine, Bratislava, Slovakia

Email: Tanja Grimm - hogger@pzlc.uni-wuerzburg.de; Roswitha Skrabala - hogger@pzlc.uni-wuerzburg.de;

Zuzana Chovanová - zuzana.chovanova@fmed.uniba.sk; Jana Muchová - zdenka.durackova@fmed.uniba.sk;

Katarína Sumegová - zdenka.durackova@fmed.uniba.sk; Anna Liptáková - zdenka.durackova@fmed.uniba.sk; Zdeňka Ď

uračková - zdenka.durackova@fmed.uniba.sk; Petra Högger* - hogger@pzlc.uni-wuerzburg.de

* Corresponding author

Published: 03 August 2006

BMC Clinical Pharmacology 2006, 6:4 doi:10.1 186/1472-6904-6-4

This article is available from: http://www.biomedcentral.com//472-6904/6/4

(c) 2006 Grimm et al; licensee BioMed Central Ltd.

This is an Open Access article distributed under the terms of the Creative Commons Attribution License (http://creativecommons.org/licenses/by/2.0), which permits unrestricted use, distribution, and reproduction in any medium, provided the original work is properly cited.
Received: 04 February 2006

Accepted: 03 August 2006

\begin{abstract}
Background: Since plant extracts are increasingly used as phytotherapeutics or dietary supplements information on bioavailability, bioefficacy and safety are warranted. We elucidated the plasma kinetics of genuine extract components and metabolites after single and multiple ingestion of the standardized maritime pine bark extract Pycnogenol (USP quality) by human volunteers.

Methods: Eleven volunteers received a single dose of $300 \mathrm{mg}$ pine bark extract, five volunteers ingested $200 \mathrm{mg}$ daily for five days to reach steady state concentrations. Plasma samples were obtained before and at defined time points after intake of the extract. Samples were analyzed by HPLC with ion-pair reagents and simultaneous UV and electrochemical detection.

Results: We quantified total plasma concentrations of catechin, caffeic acid, ferulic acid, taxifolin and the metabolite $M I$ ( $\delta$-(3,4-dihydroxy-phenyl)- $\gamma$-valerolactone). Additionally, we describe plasma time courses and steady state appearance of ten so far unknown compounds, UI to UIO. After single ingestion, compounds derived from the extract were rapidly absorbed and the majority of them were detectable over whole experimental period of $14 \mathrm{~h}$. The analysis of steady state plasma samples revealed significant phase II metabolism.

Conclusion: We present the first systematic pharmacokinetic analysis of compounds derived from maritime pine bark extract. Beyond the known constituents and metabolites we uncovered the plasma time courses of ten unknown compounds. In concert with our previous detection of anti-inflammatory bioefficacy of these plasma samples ex vivo we suggest that constituents and metabolites of Pycnogenol bear potential for disclosure of novel active principles.
\end{abstract}




\section{Background}

Since plant extracts are increasingly used as phytotherapeutics or dietary supplements information on bioavailability, bioefficacy and safety are warranted. Safety studies concerning herbal extracts mostly focus on their impact on metabolic enzyme activity and interactions with defined chemical drugs $[1,2]$. Bioefficacy of plant extracts is progressively investigated in human intervention studies [3], although there is room for improvement regarding methodological quality, sample size, and number of trials [4]. Bioavailability studies are essential completions for the understanding of risk-benefit values and mode of action of herbal remedies. Investigations of kinetics and extent of extract absorption in humans usually focus on a single or some few known lead compounds [5,6]. Only a few studies consider kinetics after single and repeated intake of the respective herbal extract $[7,8]$.

One potential difficulty for the elucidation of both bioavailability and physiological effects of plant extracts is their varying composition that derives from production under different protocols or procedures. Therefore, standardization of the extract is the basis of a reproducible results and effects that relate to batch, preparation, variety and species of the plant [9]. One approach towards quality control of plant extracts is the description of tests, analytical procedures, and acceptance criteria in monographs of internationally accepted pharmacopeias, such as the United States Pharmacopeia (USP). The USP provides the latest FDA-enforceable standards of quality, identity, strength, and purity for drug ingredients, dosage forms, medical devices, and recently also various plant extracts.

An extract with quality specified in the USP 28 is maritime pine bark extract [10]. A standardized bark extract that complies with this monograph is derived from of Pinus pinaster, Ait., (Pycnogenol ${ }^{\circledast}$, Horphag Research Ltd., UK). About $65-75 \%$ of the Pycnogenol extract are procyanidins that consist of catechin and epicatechin subunits of varying chain lengths [11]. Other constituents are polyphenolic monomers, phenolic or cinnamic acids and their glycosides.

The procyaninidine-rich maritime pine bark extract Pycnogenol exhibited diverse pharmacological actions in human trials [11]. These effects include, but are not limited to cardiovascular or anti-inflammatory bioefficacy. After oral administration to human patients Pycnogenol exerted effects on circulatory functions such as inhibition of platelet aggregation, a moderate antihypertensive effect and improved microcirculation [11,12]. Anti-inflammatory effects of maritime pine bark extract were observed in asthma patients $[13,14]$.
Though clinical effects of Pycnogenol have been documented little is known about absorption of extract constituents and their metabolism. After oral administration of Pycnogenol ferulic acid and taxifolin were detected in urine after treatment of samples with sulfatase and glucuronidase [15]. Both taxifolin and ferulic acid are genuine components of Pycnogenol. In the same experimental setting two metabolites that were not originally present in the pine bark extract were identified as $\delta$-(3,4-dihydroxyphenyl)- $\gamma$-valerolactone and $\delta$-(3-methoxy-4-hydroxyphenyl)- $\gamma$-valerolactone [15]. Free and conjugated ferulic acid was also detected in urine samples of volunteers after intake of Pycnogenol in another study [16]. The authors suggested ferulic acid as a marker compound for consumption of maritime pine bark extract.

So far, however, no information regarding the time course of constituents' or metabolites' concentration of Pycnogenol in plasma was available. The purpose of the present study was to elucidate the kinetics and rate of absorption of genuine extract components and metabolites after single and multiple ingestion of the pine bark extract by human volunteers. Thereby, we aimed to describe the time course of known and any so far unknown compounds to generate basic information for understanding bioavailability and bioefficacy of Pycnogenol.

\section{Methods \\ Volunteers}

Healthy female and male volunteers aged 18 to 30 years participated in this study. Both study protocols were approved by the ethical committee of the Comenius University's Faculty of Medicine, Bratislava, Slovak Republic, and all participants gave written informed consent.

\section{Protocol of single intake of Pycnogenol}

Eleven volunteers (five female and six male) participated in this study. After a 24 hour diet free of flavonoids (no vegetables, fruits and fruit juices or marmalades, tea, coffee, cocoa, wine and beer) a venous blood catheter was inserted into an antecubital vein and blood samples were drawn to obtain basal values ( $\mathrm{t}=0 \mathrm{~h}$ at 8:00 a.m.). Subsequently, the volunteers received a single dose of six $50 \mathrm{mg}$ tablets (preparation of study medication by DKSH, Market intelligence, Tokyo, Japan) containing 300 mg standardized maritime pine bark extract (Pycnogenol ${ }^{\oplus}$, Horphag Research Ltd., UK) with $200 \mathrm{~mL}$ tap water. At $8: 15$ a.m. the volunteers had a standardized breakfast (two white rolls (bread) and $0.3-0.5 \mathrm{~L}$ of milk (1.5\% fat)), at 12:15 lunch (1/4 of only salted and baked chicken with white bread) and at $6: 15$ p.m. dinner ( $100 \mathrm{~g}$ ham, 50 $\mathrm{g}$ cheese (eidam) and bread with butter or margarine). After each blood sampling mineral water was served. Blood samples were obtained at $\mathrm{t}=0.5 \mathrm{~h}, 1 \mathrm{~h}, 2 \mathrm{~h}, 4 \mathrm{~h}, 6$ h, 8 h, 10 h, $12 \mathrm{~h}$ and $14 \mathrm{~h}$. Samples were centrifuged and 
plasma was aliquoted, shock frozen and stored at $-80^{\circ} \mathrm{C}$ until further analysis.

\section{Protocol of repeated intake of Pycnogenol}

Five volunteers (four female and one male) participated in this study. After a 24 hour diet free of flavonoids blood samples were drawn to obtain basal values. Subsequently, the volunteers took four $50 \mathrm{mg}$ tablets containing $200 \mathrm{mg}$ Pycnogenol every morning for five days to reach steady state conditions of constituents and/or metabolites of Pycnogenol. It was assumed that steady state plasma concentrations were reached after 5 days.

Four hours after the last intake of Pycnogenol on day five a second blood sample was obtained from each volunteer. Again, a 24 hour period of a diet free of flavonoids preceded this blood sampling. Blood samples were centrifuged and plasma was aliquoted, shock frozen and stored at $-80^{\circ} \mathrm{C}$ until further analysis.

\section{Chemicals and reagents}

A spray-dried extract from maritime pine bark (Pycnogenol $^{\circledR}$ ) was generously provided by Horphag Research Ltd. (Geneva, Switzerland). The metabolites M1 ( $\delta$-(3,4-Dihydroxy-phenyl)- $\gamma$-valerolactone) and M2 ( $\delta$-(3-Methoxy-4hydroxy-phenyl)- $\gamma$-valerolactone) were synthesized by Große Düweler[15] The monomeric compounds (+)-catechin, (-)-epicatechin, ferulic acid, gallic acid, 4-hydroxybenzoic acid, caffeic acid, protocatechuic acid, sinapic acid und $( \pm)$-taxifolin were purchased from Sigma-Aldrich (St. Louis, MO, USA). All other chemicals were obtained from Sigma-Aldrich or Merck (Darmstadt, Germany), if not stated otherwise. All chemicals used were of highest purity available.

Krebs-Ringer-HEPES buffer ( $\mathrm{pH} 7.4$ ) consisted of $118 \mathrm{mM}$ $\mathrm{NaCl}, 4.84 \mathrm{mM} \mathrm{KCl}, 1.2 \mathrm{mM} \mathrm{KH}{ }_{2} \mathrm{PO}_{4}, 2.43 \mathrm{mM} \mathrm{MgSO}_{4}$, $2.44 \mathrm{mM} \mathrm{CaCl}_{2} \times 2 \mathrm{H}_{2} \mathrm{O}$ and $10 \mathrm{mM}$ HEPES.

\section{Preparation of plasma samples}

Plasma samples of $2.0 \mathrm{~mL}$ were prepared for analysis. For determination of total plasma concentration, to each sample $20 \mathrm{U} \beta$-glucuronidase (type $\mathrm{H}-3$ from Helix pomatia; EC 3.2.1.31) and $20 \mathrm{U}$ sulfatase (type $\mathrm{H}-1$ from Helix pomatia; EC 3.1.6.1) were added in $50 \mathrm{mM}$ sodium acetate buffer ( $\mathrm{pH} 5.0$ ) and incubated for $2 \mathrm{~h}$ at $37^{\circ} \mathrm{C}$ under gentle shaking. Samples for determination of free plasma concentrations were prepared without prior incubation with enzymes. Each $20 \mu \mathrm{L}$ of p-hydroxybenzoic acid methylester $(100 \mu \mathrm{g} / \mathrm{mL}$; for HPLC UV detection) and hydrochinone $(10 \mu \mathrm{g} / \mathrm{mL}$; for HPLC electrochemical detection) were added as internal standards and samples were acidified with $100 \mu \mathrm{L} 1 \mathrm{M}-\mathrm{HCl}$. Samples were extracted twice with each $3 \mathrm{~mL}$ acetic acid methylester for $20 \mathrm{~min}$, using a roller mixer, followed by centrifugation $\left(20^{\circ} \mathrm{C}\right) 5 \mathrm{~min}$. The organic phases of both extractions were separated, combined and evaporated to dryness under a gentle stream of nitrogen at $25^{\circ} \mathrm{C}$. The resulting residue was reconstituted in $100 \mu \mathrm{L}$ methanol and subjected to HPLC analysis.

Calibration curves of all known compounds of Pycnogenol were prepared by addition of the respective substances to $2.0 \mathrm{~mL}$ of Krebs-Ringer-HEPES buffer ( $\mathrm{pH}$ 7.4). This was necessary because sufficient volumes of pooled blank plasma of blood donors who kept a 24 hour diet free of flavonoids was not available (total volume needed was about $800 \mathrm{~mL}$ for all experiments). Thus, buffer instead of plasma was used and treated analogously as plasma samples from volunteers. Since initial control experiments revealed that the incubation with $\beta$-glucuronidase and sulfatase did not produce interfering peaks in the HPLC chromatograms no enzymes were added to calibration curve samples.

\section{Analysis of plasma samples by HPLC - UVlelectrochemical dual detection}

The HPLC system was a Waters HPLC (Milford, MA, USA) consisted of a 1525 binary pump, a 717plus autosampler, a 2487 dual wavelength absorbance detector set at the detection wavelength of $280 \mathrm{~nm}$ and an electrochemical detector CLC 100 (Chromsystems, Munich, Germany) set at an oxidation voltage of $0.5 \mathrm{~V}$. The second detector was connected to the control system by a satellite interface (Waters). Data collection and integration were accomplished using Breeze ${ }^{\mathrm{TM}}$ software version 3.30. Analysis was performed on a Zorbax SB $\mathrm{C}_{8}$ column $(150 \times 4.6 \mathrm{~mm}$ I.D., $5 \mu \mathrm{m}$ particle size, Agilent Technologies, Palo Alto, CA, USA).

Typically, $20 \mu \mathrm{L}$ of sample were injected and separated at a flow rate of $1 \mathrm{~mL} / \mathrm{min}$. Isocratic elution was performed using water (containing $0.6 \mathrm{mM}$ 1-octanesulfonic acid sodium salt, $0.27 \mathrm{mM}$ ethylenediaminetetraacetic acid disodium salt, $0.04 \mathrm{M}$ triethylamine; $\mathrm{pH} 2.95$ adjusted with phosphoric acid) and acetonitrile (ACN, HPLC gradient quality, Fisher Scientific, Schwerte, Germany). Method A (for UV detection of ferulic acid, M2 ( $\delta$-(3Methoxy-4-hydroxy-phenyl)- $\gamma$-valerolactone), U1, U2, U3, U4, U7, U8, and U9) used water/ACN at 85:15 (v/v). Method B (for electrochemical detection of catechin, caffeic acid, taxifolin, M1 ( $\delta$-(3,4-dihydroxy-phenyl)- $\gamma$ valerolactone), U1, U2, U4, U5, U6, U8, U9 and U10) used water/ACN at $88: 12(\mathrm{v} / \mathrm{v})$.

The analytical method was validated according to ICH guidelines. The method fulfilled the quality criteria for selectivity, linearity, precision and accuracy. The calibration curves' working range was $0.5-20 \mathrm{ng} / \mathrm{mL}$ for caffeic acid, $1-50 \mathrm{ng} / \mathrm{mL}$ for $\mathrm{M} 1,10-100 \mathrm{ng} / \mathrm{mL}$ for catechin, 
taxifolin and ferulic acid, 50-200 ng/mL for M2. The recovery rates after extraction were $83.1 \%(\mathrm{M} 2)$ to $98.0 \%$ (taxifolin). The lower limits of quantitation were $0.5 \mathrm{ng} /$ $\mathrm{mL}$ for caffeic acid, $1 \mathrm{ng} / \mathrm{mL}$ for $\mathrm{M} 1,10 \mathrm{ng} / \mathrm{mL}$ for catechin, taxifolin and ferulic acid, $50 \mathrm{ng} / \mathrm{mL}$ for $\mathrm{M} 2$.

\section{Quantitation of pine bark extract constituents in tablets by HPLC - UV detection}

Pycnogenol tablets prepared for this study (see above) were pounded and suspended in methanol to yield concentrations of $1 \mathrm{mg} / \mathrm{mL}$, vortexted for 2 minutes, centrifuged and the supernatant collected. The procedure was repeated 4 times. The amount of taxifolin, ferulic acid, caffeic acid and catechin in the Pycnogenol tablets administered to the volunteers was calculated on the basis of calibration curves. They were constructed with five concentrations ranging from $5-20 \mu \mathrm{g} / \mathrm{mL}$ for taxifolin, from $1-10 \mu \mathrm{g} / \mathrm{mL}$ for ferulic acid, and from $0.1-8 \mathrm{mg} / \mathrm{mL}$ for caffeic acid. Analysis was performed on an Atlantis C-18d column $(150 \times 3.9 \mathrm{~mm}$ i.d, $3 \mu \mathrm{m}$ particle size; Waters $)$. The mobile phase consisted of water containing $1 \%$ acetic acid (A) and acetonitrile (B). The gradient elution started at $98 \%$ eluent A increasing linearly to $84 \%$ within 60 minutes and a flow rate of $1 \mathrm{~mL} / \mathrm{min}$. The $\mathrm{UV}$ detection wavelength was set to $280 \mathrm{~nm}$.

\section{Results \\ Detection of Pycnogenol constituents and metabolites in plasma}

After oral ingestion of either a single dose of $300 \mathrm{mg}$ or multiple doses of $200 \mathrm{mg}$ plasma concentrations of constituents or metabolites of Pycnogenol were detectable in all volunteers without exception. Unless otherwise indicated, plasma levels repesent the sum of free and conjugated compounds. After $300 \mathrm{mg}$ single dose intake a mean of $11 \pm 2$ (range 7-14) different constituents or metabolites were found in the plasma samples of each volunteer. After $200 \mathrm{mg}$ multiple dose intake a mean of $7 \pm 2$ (range 4-10) different constituents or metabolites were detected in the plasma sample of each volunteer. A total of 15 different compounds were detectable after single dose intake. Of those substances detected after single dose intake, 12 compounds were also found in plasma samples after multiple dose ingestion.

Of the 15 compounds that were present in plasma samples 5 were known constituents or metabolites of Pycnogenol (catechin, caffeic acid, ferulic acid, taxifolin and M1 ( $\delta$-(3,4-dihydroxy-phenyl)- $\gamma$-valerolactone), Figure 1). The other 10 compounds were unknown, they were not identical with any previously described component of maritime pine bark extract, e.g. coumaric acid, (-)-epicatechin, gallic acid, 4-hydroxybenzoic acid, protocatechuic acid or M2 ( $\delta$-(3-Methoxy-4-hydroxy-phenyl)- $\gamma$-valerolactone). The 10 unknown compounds were labelled as U1<smiles>Oc1cc(O)c2c(c1)O[C@H](c1ccc(O)c(O)c1)[C@H](O)C2</smiles>

(+) Catechin<smiles>O=C(O)/C=C/c1ccc(O)c(O)c1</smiles>

Caffeic acid<smiles>O=C1c2c(O)cc(O)cc2O[C@@H](c2ccc(O)c(O)c2)C1O</smiles>

Taxifolin<smiles>COc1cc(/C=C/C(=O)O)ccc1O</smiles>

Ferulic acid

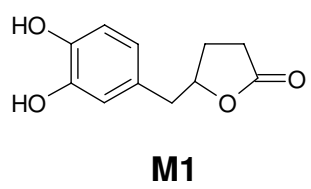

Figure I

Structural formulas of the known compounds that were detected in plasma samples of volunteers after intake of Pycnogenol.

to $\mathrm{U} 10$ according to their retention time at the reversedphase HPLC column. The compound U1 was eluted after $4.5 \mathrm{~min}, \mathrm{U} 2$ after $5.4 \mathrm{~min}, \mathrm{U} 3$ after $13.4 \mathrm{~min}$, U4 after $14.3 \mathrm{~min}$, U5 after $15.5 \mathrm{~min}$, U6 after $16.2 \mathrm{~min}$, U7 after $17.2 \mathrm{~min}$, U8 after $20.8 \mathrm{~min}$, U9 after $22.2 \mathrm{~min}$ and U10 after $35.8 \mathrm{~min}$. For all unknown substances the peak area ratios of the respective compound to the internal standard were calculated which allowed graphical representation of the time course in plasma.

\section{Pycnogenol constituents and metabolites in plasma after a single dose of $300 \mathrm{mg}$}

Compounds with $t_{\max }$ up to 5 hours

Four compounds found in the plasma samples after single intake of $300 \mathrm{mg}$ Pycnogenol displayed early maximum concentrations up to five hours and were measurable over the whole time period of $14 \mathrm{~h}$ (Figure 2). Catechin was detectable rapidly with mean concentrations of about 60 $\mathrm{ng} / \mathrm{mL}$ after $0.5 \mathrm{~h}$ already. Thereafter, the time course revealed gradually increasing concentrations to about 100 $\mathrm{ng} / \mathrm{mL}$ after $4 \mathrm{~h}$ and subsequent decrease of plasma levels. However, catechin was detectable over the whole period of time. The plasma concentrations were almost constant from 6 to $14 \mathrm{~h}$. A similar time course, but significantly lower of plasma concentrations were seen for caffeic acid. Maximum plasma concentrations of ferulic acid were seen already after 0.5 to $1 \mathrm{~h}$. Concentrations decreased thereaf- 

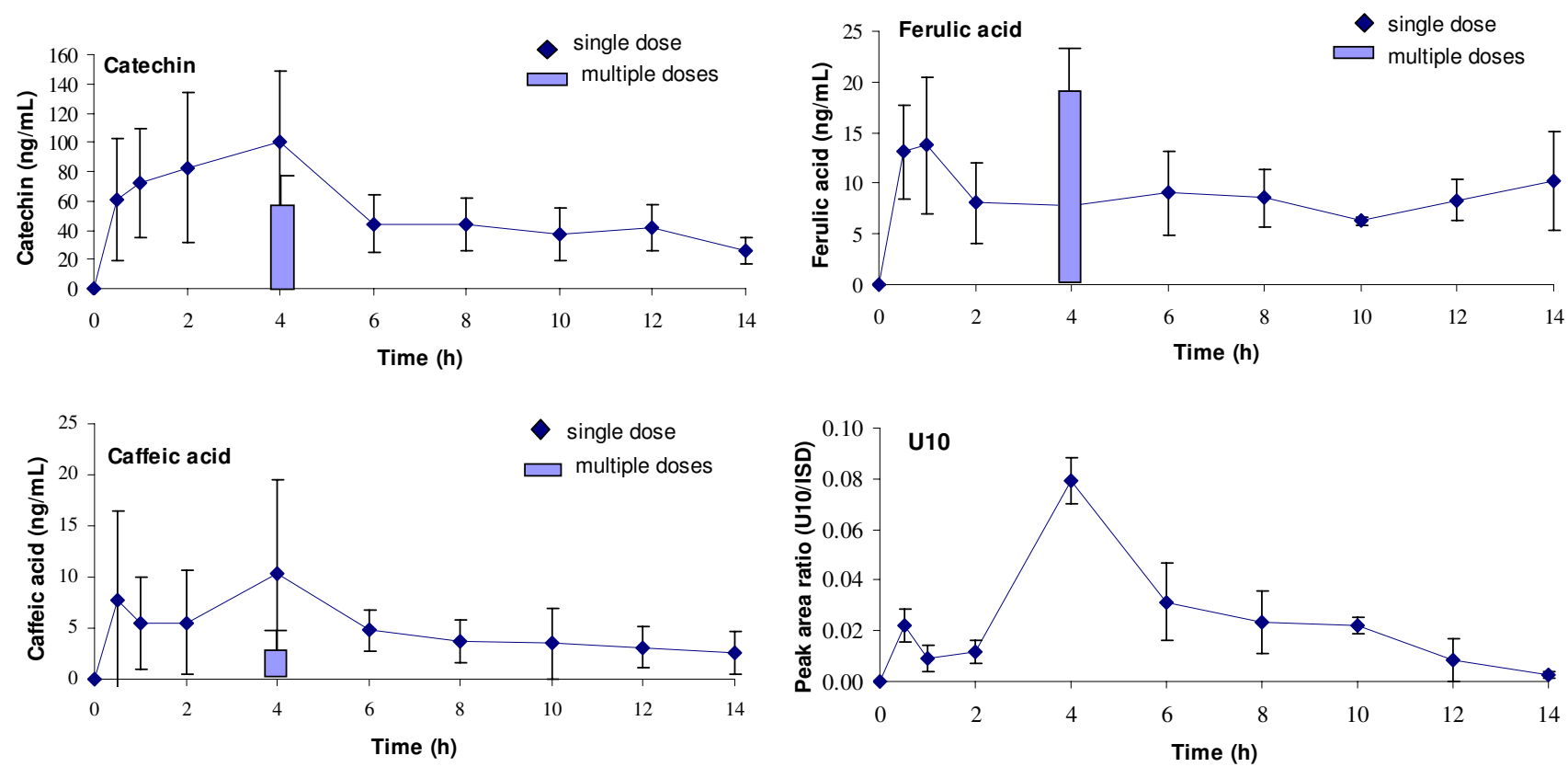

\section{Figure 2}

Time course of total (free and conjugated) plasma concentrations of catechin, caffeic acid, ferulic acid and UI0. These compounds revealed an early $t_{\max }$ (time of maximal plasma concentration) up to five hours after intake of the pine bark extract. Symbols represent time course of mean and standard deviation of concentrations after a single dose of $300 \mathrm{mg}$ Pycnogenol. The columns represents mean and standard deviation of concentrations after repeated doses of $200 \mathrm{mg}$ Pycnogenol daily after five days (assumed steady state). Steady state concentrations of UIO were detectable in only two volunteers and are not shown in this diagram.

ter and remained almost constant before revealing another increase towards the end of experimental period. The unknown compound U10 was present in the plasma samples after $0.5 \mathrm{~h}$ as well, but maximum concentrations were reached not before $4 \mathrm{~h}$. Thereafter, the plasma levels steadily decreased and U10 appeared to be almost eliminated after $14 \mathrm{~h}$.

\section{Compounds with $t_{\max }$ between 5 and 10 hours}

Three compounds displayed maximum plasma levels between 5 and $10 \mathrm{~h}$ after intake of Pycnogenol tablets (Figure 3). Taxifolin was not detectable before $2 \mathrm{~h}$, maximum concentrations were recorded after $8 \mathrm{~h}$. Thereafter, the taxifolin levels remained almost constant until the end of the experimental period. Both unknown compounds $U 8$ and $U 9$ appeared rather late after $6 \mathrm{~h}$ in plasma and both were rapidly eliminated with no measurable concentrations after $14 \mathrm{~h}$.

\section{Compounds with $t_{\max }$ around 10 hours}

Three compounds showed late maximum plasma levels $10 \mathrm{~h}$ after intake of Pycnogenol tablets (Figure 4). One was the previously identified metabolite M1 $(\delta$-(3,4-dihydroxy-phenyl)- $\gamma$-valerolactone) that has been found in urine samples before [15]. Consistent with the notion that it is formed in vivo from catechin by bacterial metabolism this substance appeared late in plasma. It was detectable after $6 \mathrm{~h}$, revealed a peak concentration around $10 \mathrm{~h}$ (mean concentration $3.59 \mathrm{ng} / \mathrm{mL}$ ) and was still present 14 $\mathrm{h}$ after Pycnogenol ingestion. Two further compounds of unknown identity displayed a similar time course with a $\mathrm{t}_{\max }$ around $10 \mathrm{~h}$, but the plasma concentrations of U5 and U6 decreased towards the end of the experimental period.

\section{Compounds with interindividually highly variable $t_{\max }$}

Five unknown compounds revealed time courses after intake of Pycnogenol with pronounced interindividual variability in time of maximum concentrations (Figure 5). When mean concentrations were calculated, the mean time course thus appeared to display either no pronounced or multiple $t_{\text {max }^{\prime}}$ e.g. apparently three $t_{\max }$ for U4 . However, when the time course of the plasma concentrations of individual volunteers was inspected, it revealed always two $\mathrm{t}_{\text {max }^{\prime}}$ one early $\mathrm{t}_{\max }$ between 0.5 to $2 \mathrm{~h}$ and one late $\mathrm{t}_{\max }$ between 8 and $12 \mathrm{~h}$. All five substances, U1 to U4 and U7 were detectable over the whole experimental period. All were readily present in the plasma samples, 

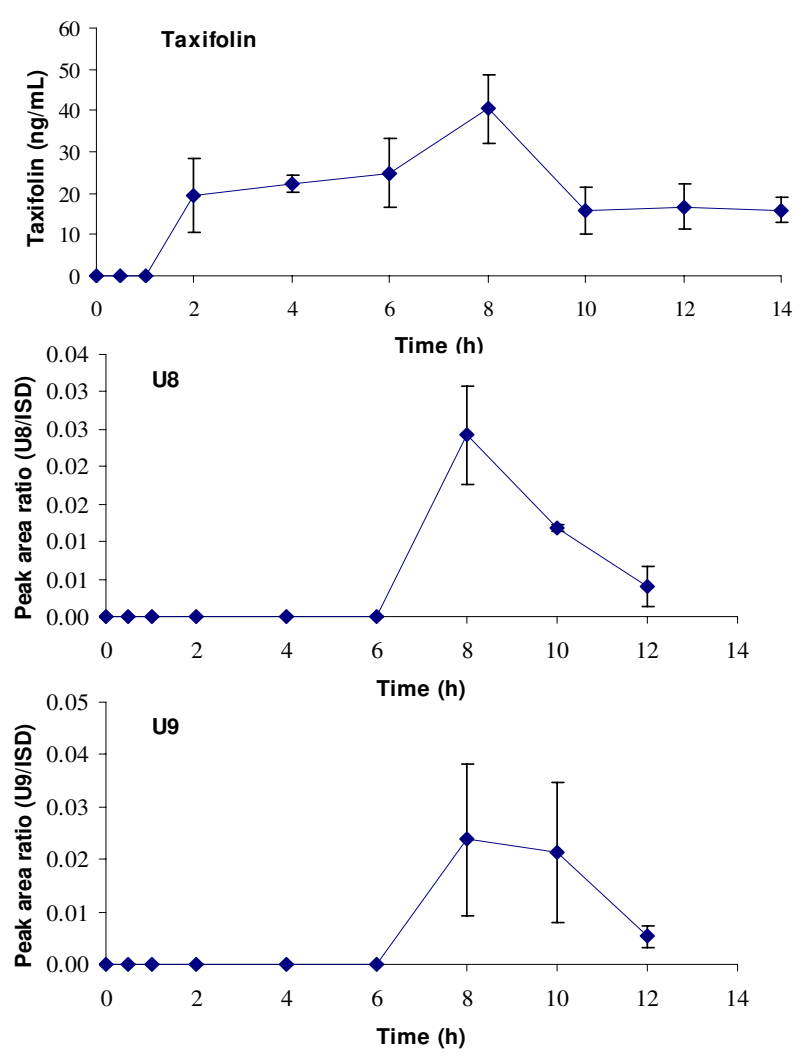

Figure 3

Time course of total (free and conjugated) plasma concentrations of taxifolin, U8 and U9. These compounds had a $t_{\max }$ between five and ten hours. Symbols represent time course of mean and standard deviation of concentrations after a single dose of $300 \mathrm{mg}$ Pycnogenol. No steady state concentrations after repeated doses of $200 \mathrm{mg}$ Pycnogenol daily were detectable after five days.

especially $U 3$ and $U 7$ revealed high concentrations $0.5 \mathrm{~h}$ after ingestion of Pycnogenol already.

\section{Pycnogenol constituents and metabolites in plasma after} multiple doses of $\mathbf{2 0 0} \mathbf{~ m g}$

Most constituents or metabolites that were detected in the volunteers' plasma samples after intake of a $300 \mathrm{mg}$ single dose were also found after repeated intake of $200 \mathrm{mg}$ Pycnogenol (columns in Figures 2, 3, 4, 5). Plasma samples were obtained $4 \mathrm{~h}$ after the last dose of Pycnogenol. It was assumed that steady state conditions were reached after five days ingestion of the pine bark extract. Steady state concentrations of all compounds except for taxifolin, U8 and U9 were detectable at least in one volunteer. However, only when steady state concentrations of a constituent or metabolite in the plasma of at least three volunteers were measurable, these are shown as columns in the graphical plots. Thus, no data are shown for U1 (two
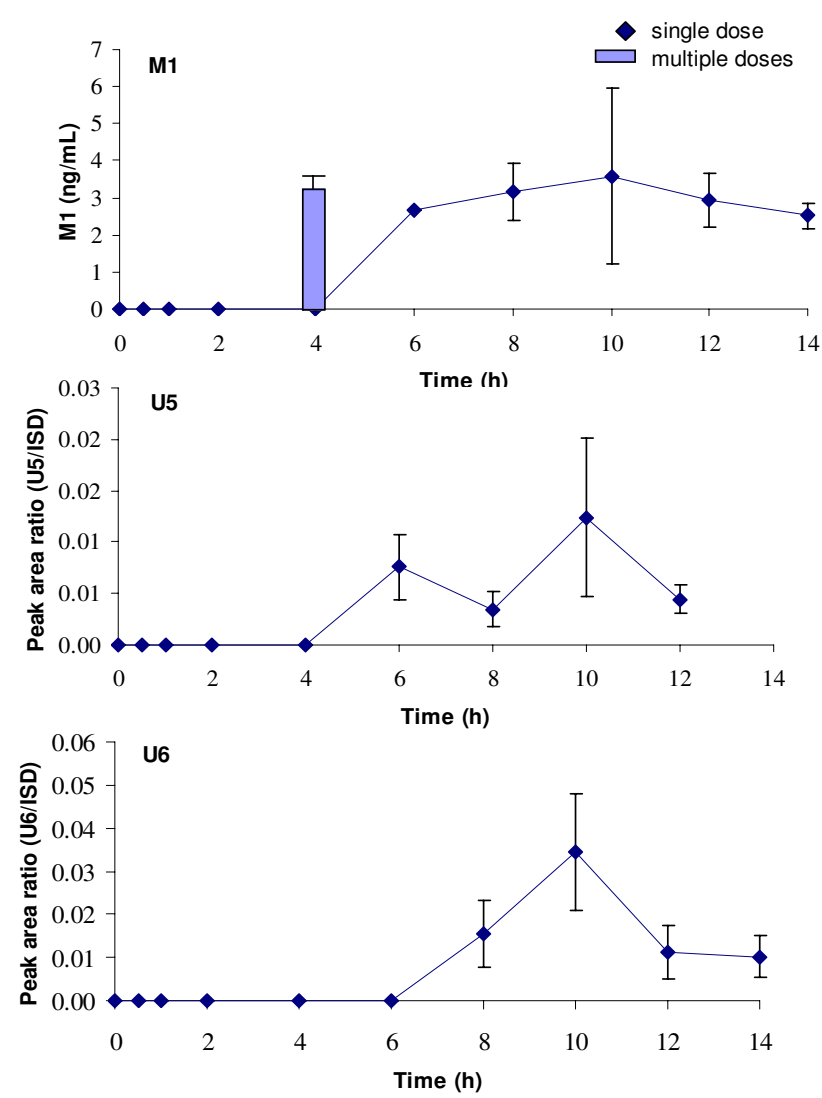

Figure 4

Time course of total (free and conjugated) plasma concentrations of MI, U5 and U6. These compounds had a $t_{\max }$ around ten hours. Symbols represent time course of mean and standard deviation of concentrations after a single dose of $300 \mathrm{mg}$ Pycnogenol. The column represents mean and standard deviation of $\mathrm{MI}$ concentrations after repeated doses of $200 \mathrm{mg}$ Pycnogenol daily after five days. Steady state concentrations of U5 and U6 were detectable in one, respectively two volunteers and are not shown in this diagram.

plasma samples with measurable concentrations), U5 (one sample), U6 (two samples), U10 (two samples). Plasma concentrations of taxifolin, U8 and U9 were below the limit of quantitation for all volunteers after the multiple doses of $200 \mathrm{mg}$. For most compounds the mean steady state plasma concentration was well within the range of individual variability in concentrations measured after single ingestion of the pine bark extract. One exception is the metabolite $\mathrm{M} 1$ which revealed mean steady state plasma concentrations $(3.01 \mathrm{ng} / \mathrm{mL})$ which were similar to concentrations measured after single intake of Pycnogenol. 

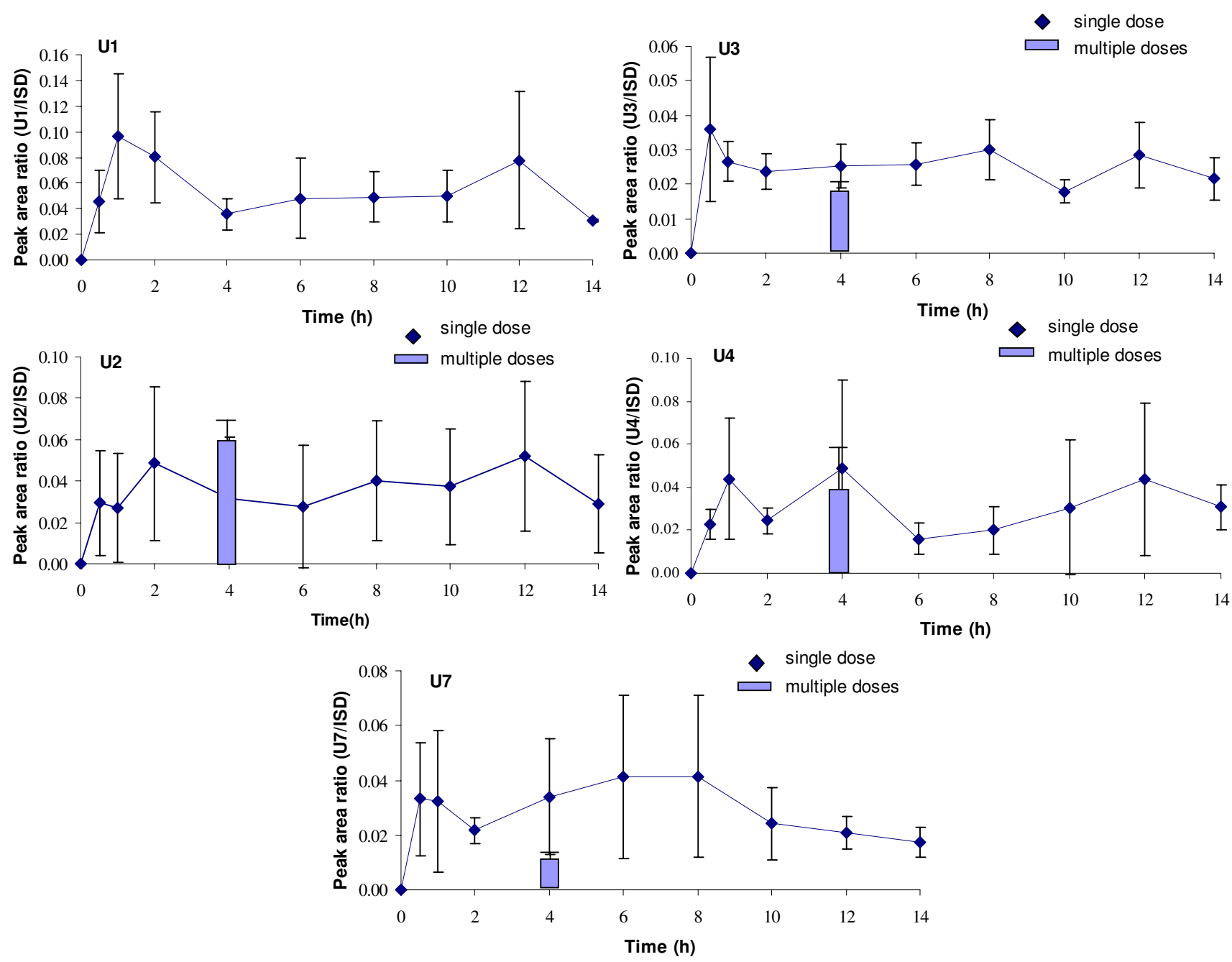

\section{Figure 5}

Time course of total (free and conjugated) plasma concentrations of UI, U2, U3, U4 and U7. These compounds revealed high interindividual variability of the $t_{\max }$. Symbols represent time course of mean and standard deviation of concentrations after a single dose of $300 \mathrm{mg}$ Pycnogenol. The columns represent mean and standard deviation of concentrations after repeated doses of $200 \mathrm{mg}$ Pycnogenol daily after five days. Steady state concentrations of $U$ I were detectable in only two volunteers and are not shown in this diagram.

\section{Individual degree of conjugation with sulfate and glucuronic acid}

The plasma samples obtained after repeated intake of 200 mg Pycnogenol daily were additionally analyzed for the degree of conjugation with sulfate and glucuronic acid. This type of phase II metabolism has been described for Pycnogenol constitutents and metabolites [15,16]. Generally, the chomatograms of plasma samples that were not pre-incubated with sulfatase and glucuronidase revealed less and smaller compound peaks. The degree of conjugation displayed significant interindividual variability. Data of compounds that revealed detectable total plasma concentrations and a degree of conjugation less than $100 \%$ are listed in Table 1 . For catechin, the range was $0 \%$ conjugated (volunteer 4 ) to $\approx 100 \%$ conjugated (volunteer $3)$. The other volunteers revealed $43.3 \%, 66.8 \%$ and 72.3 $\%$ conjugation of catechin (mean percentage of conjugation $56.5 \%$ ). Three volunteers had detectable plasma concentrations of free caffeic acid. The individual degree of conjugation was $59.6 \%, 61.5 \%$ and $87.6 \%$ (mean $69.4 \%$ ). The unknown compound U2 was highly conjugated; two volunteers' samples were $\approx 100 \%$ conjugated, the other $32.4 \%, 68.5 \%$ and $84.7 \%$ (mean $77.1 \%$ ). Only three volunteers had detectable plasma concentrations of U7. The individual degree of conjugation was $17.3 \%, 46.3 \%$ and $71.4 \%$ for U7 (mean $45 \%$ ). Total 
plasma concentrations of M1 $(\mathrm{n}=3)$, ferulic acid $(\mathrm{n}=3)$, U1 $(\mathrm{n}=2)$, U3 $(\mathrm{n}=3), \mathrm{U} 4(\mathrm{n}=4)$, U5 $(\mathrm{n}=1), \mathrm{U} 6(\mathrm{n}=2)$ and $U 10(n=2)$ were detectable in some of the volunteers. Since no free concentrations were found we conclude that these compounds were about $100 \%$ conjugated. Plasma concentrations of taxifolin, U8 and U9 were below the lower limit of quantitation in all volunteers.

\section{Analysis of Pycnogenol in tablets used in the study}

The quality of the Pycnogenol tablets used in this study was analyzed according to the USP 28 monograph [10]. The tablets were in conformity with the acceptance criteria defined in the monograph. In order to calculate pharmacokinetic parameters it was necessary to quantify the content of known single nonconjugated extract components. Therefore, the tablets were subjected to HPLC analysis and content of single compounds was calculated based on calibration curves with the pure compound. The calculated content was $1.75 \mu \mathrm{g}$ free caffeic acid per mg extract in the study medication, $3.25 \mu \mathrm{g}$ free ferulic acid per mg extract and $14.35 \mu \mathrm{g}$ free taxifolin per mg Pycnogenol.

\section{Pharmacokinetic parameters of compounds detected after single dose intake}

From individual time courses after administration of 300 mg Pycnogenol as a single dose pharmacokinetic parameters were calculated. Mean and standard deviations of individual results were summarized (Table 2). For caffeic acid (calculated dose administered: $0.525 \mathrm{mg}$ ), taxifolin (calculated dose: $4.31 \mathrm{mg}$ ) and ferulic acid (calculated dose: $0.975 \mathrm{mg}$ ) the AUC, $c_{\max }, t_{\max }$ and terminal $t^{1 / 2}$ were determined. These calculations were based on the determined free concentration of the respective compound in the extract and based on the assumption that no additional caffeic or ferulic acid was metabolically generated. For both catechin and metabolite $\mathrm{M} 1$ only $\mathrm{c}_{\max }$ and $\mathrm{t}_{\max }$ were calculated. Since unknown amounts of additional catechin besides genuinely contained monomeric catechin might be generated by metabolic breakdown of higher procyanidin oligomers [17] no additional parameters could be determined. Likewise, because M1 is gener- ated from catechin units $[15,17]$ the dose administered was unknown.

\section{Discussion}

In the present investigation we present the results of an extensive analysis of plasma concentrations of constituents and metabolites of standardized maritime pine bark extract (Pycnogenol) after single and multiple administrations to healthy human volunteers. After ingestion, compounds derived from the extract were absorbed by all volunteers. We quantified the plasma concentrations of catechin, caffeic acid, ferulic acid, taxifolin and the metabolite M1 ( $\delta$-(3,4-dihydroxy-phenyl)- $\gamma$-valerolactone). Additionally, we describe plasma time courses and steady state appearance of ten so far unknown compounds, U1 to U10.

The oral bioavailability of molecules with drug-like properties depends on their physicochemical properties which have been described as the "rule of five" [18]. Absorption is most probable if a compound has less than 5 hydrogen bond donors, less than 10 hydrogen acceptors, a relative molecular mass below 500 and a $\log P$ smaller than 5 . Exceptions from this rule are known for many orally active drugs which often share structural similarity with substrates of specific transporters which enable enhanced absorption. All monomeric polyphenols detected in plasma samples in the present study comply with the "rule of five" and thus their bioavailability might not appear surprising. However, since these genuine compounds of the maritime pine bark extract represent only a small fraction of the whole extract their presence in plasma samples substantiates that the excess of higher procyanidin oligomers does not interfere with absorption of smaller molecules. Plasma concentrations of caffeic acid, ferulic acid and taxifolin were well detectable although the calculated intake of the respective compounds was only between 0.5 and $4 \mathrm{mg}$ after a $300 \mathrm{mg}$ Pycnogenol dose.

Catechin levels were readily detectable in plasma samples of the volunteers after single and multiple intake of Pyc-

Table I: Detectable plasma concentrations of compounds that revealed a mean degree of phase II conjugation of less than I00\%: catechin $(n=5)$, caffeic acid $(n=3), U_{2}(n=5)$ and $U 7(n=3)$ in samples of volunteers after repeated intake of $200 \mathrm{mg}$ Pycnogenol once daily for five days.

\begin{tabular}{ccrr}
\hline & Total plasma concentration & Free plasma concentration & $\%$ conjugated \\
\hline Catechin $[\mathrm{ng} / \mathrm{ml}]$ & $48.6 \pm 16.7$ & $21.0 \pm 13.1$ & $56.5 \pm 27.9$ \\
Caffeic acid [ng/ml] & $2.42 \pm 1.39$ & $0.56 \pm 0.02$ & $69.4 \pm 11.8$ \\
U2 [peak ratio] & $0.0537 \pm 0.0132$ & $0.0105 \pm 0.0084$ & $77.1 \pm 21.3$ \\
U7 [peak ratio] & $0.0101 \pm 0.0007$ & $0.0057 \pm 0.0020$ & $45.0 \pm 18.5$ \\
\hline
\end{tabular}

Plasma concentrations were determined with and without prior incubation of sulfatase and glucuronidase (total and free plasma concentration, respectively) and individual percentage of phase II conjugation was calculated. Mean concentrations and mean deviations of the mean are listed. 
Table 2: Calculated pharmacokinetic parameters of components or metabolites after intake of a single dose of $300 \mathrm{mg}$ Pycnogenol. Values represent means and standard deviations.

\begin{tabular}{|c|c|c|c|c|c|c|}
\hline Compound & $\mathrm{n}$ & $A \cup C_{[0-t]}[\mathrm{ng} / \mathrm{mL} \times \mathrm{h}]$ & $A \cup C_{[t-8]}[\mathrm{ng} / \mathrm{mL} \times \mathrm{h}]$ & $c_{\max }[\mathrm{ng} / \mathrm{mL}]$ & $\mathrm{t}_{\max }[\mathrm{h}]$ & term $\mathrm{t}^{1 / 2}[\mathrm{~h}]$ \\
\hline Caffeic acid & 9 & $75.66 \pm 33.53$ & $82.78 \pm 36.47$ & $16.67 \pm 13.29$ & $3.7 \pm 2.4$ & $4.42 \pm 2.47$ \\
\hline Catechin & 9 & & & $107.22 \pm 55.49$ & $3.2 \pm 1.7$ & \\
\hline Taxifolin & 6 & $231.11 \pm 85.98$ & $399.14 \pm 98.95$ & $33.34 \pm 12.54$ & $8.2 \pm 2.5$ & $8.89 \pm 2.81$ \\
\hline Ferulic acid & 7 & $99.05 \pm 28.09$ & $141.19 \pm 73.90$ & $14.78 \pm 5.89$ & $1.2 \pm \mathrm{I} . \mathrm{I}$ & $6.87 \pm 3.83$ \\
\hline MI & 8 & & & $4.11 \pm 2.08$ & $10.0 \pm 1.9$ & \\
\hline
\end{tabular}

Abbreviations: $n$ - number of volunteers with detectable compound concentrations; AUC - area under the curve, "t" symbolizes the time of last plasma sampling ( $14 \mathrm{~h})$; $\mathrm{c}_{\max }$ - maximal plasma concentration, $\mathrm{t}_{\max }$ - time of maximal plasma concentration; term $\mathrm{t}^{1 / 2}-$ terminal half-life of compound.

These calculations were based on the determined free concentration of the respective compound in the extract and based on the assumption that no additional caffeic or ferulic acid was metabolically generated.

nogenol as well. It was not possible to determine the administered "dose" of catechin. Catechin is as well genuinely present in the extract as polyphenolic monomer and might be additionally generated by metabolic breakdown of higher procyanidin oligomers [17]. In the present study the catechin plasma concentration peaked with about 100 $\mathrm{ng} / \mathrm{mL}(\approx 370 \mathrm{nmol} / \mathrm{L})$ within the first $3 \mathrm{~h}$. Maximal plasma concentrations of catechin were observed after 1.5 $\mathrm{h}$ in human plasma after ingestion of red wine or reconstituted red wine $[19,20]$ and $0.5 \mathrm{~h}$ or $2-3 \mathrm{~h}$ after intake of pure catechin $[21,22]$. Thus, the $t_{\max }$ of catechin observed in the present investigation is within the range described in other studies. In contrast to the time course of plasma levels after ingestion of the pure compound, we observed catechin over the whole experimental period and the levels remained almost constant between $6 \mathrm{~h}$ and $14 \mathrm{~h}$. This is consistent with metabolic generation of catechin [17] monomers from oligomeric procyanidins. By $4 \mathrm{~h}$ after ingestion of pure catechin the plasma concentrations were not significantly different from baseline levels [22]. After a high single dose the unchanged catechin was detected in plasma between $30 \mathrm{~min}$ and $12 \mathrm{~h}$ after administration, metabolites for a shorter period of time [21]. After a single dose of pure catechin the free polyphenol concentration was only 1.1 to $6.5 \%$ of the total concentration. We observed higher free catechin concentrations of about 56 $\%$ after multiple intake of maritime pine bark extract, but the interindividual variability was high.

Caffeic acid was present in the volunteers' plasma samples already $0.5 \mathrm{~h}$ after ingestion of Pycnogenol. This fast systemic availability is consistent with other reports $[6,23$ 25 . While we determined a $t_{\max }$ of caffeic acid between $3-$ $4 \mathrm{~h}$ others report $\mathrm{t}_{\max }$ values between $0.5-1 \mathrm{~h}$ after intake of red wine, coffee or artichoke leaf extract $[6,24,25]$ or a $t_{\max } 2 \mathrm{~h}$ after ingestion of red wine [23]. Though the $t_{\max }$ we observed appears to be slightly later than in other investigations the maximal plasma concentrations we measured were comparatively high. After a calculated intake of $525 \mu \mathrm{g}$ caffeic acid a $\mathrm{c}_{\max }$ about $17 \mathrm{ng} / \mathrm{mL}(\approx 90$ $\mathrm{nmol} / \mathrm{L}$ ) was found, which is comparable to a $c_{\max }$ of 84 $\mathrm{nmol} / \mathrm{L}$ after intake of $55 \mu \mathrm{g}$ caffeic acid per $\mathrm{kg}$ body weight [23]. After ingestion of $107 \mathrm{mg}$ caffeic acid from artichoke leaf extract a lower $c_{\max }$ of $6.5 \mathrm{ng} / \mathrm{mL}$ was reported [6]. The later $t_{\max }$ and higher $c_{\max }$ found in the present study might indicate additional sources of caffeic acid from so far not identified metabolic pathways or due to the presence of additional caffeic acid as conjugate in the pine bark extract. A 5.4 fold increase of caffeic acid concentration in beer after hydrolysis was recently described [26]. The elimination half-live of $4.42 \pm 2.47 \mathrm{~h}$ we calculated for caffeic acid is consistent with the $t^{1 / 2}$ of $3.08 \pm 1.53 \mathrm{~h}$ reported previously [6]. The degree of conjugation of caffeic acid we found after multiple intake of the maritime pine bark extract (mean $69 \%$ ) was within the range reported after single intake of coffee (around $70-80 \%$ ) [25], but lower than after or after beer ingestion (around $90 \%$ ) [26].

Ferulic acid has been previously described as a urine excretion marker of consumption of maritime pine bark extract [16] and thus it was expected to be present in plasma. We observed an early $\mathrm{t}_{\max }$ of $1 \mathrm{~h}$ for ferulic acid which is consistent with other reports of $t_{\max }$ values of 1-3 h [27] or $0.77 \mathrm{~h} \mathrm{[6]}$. The $\mathrm{c}_{\max }$ of about $15 \mathrm{ng} / \mathrm{mL}(\approx 75 \mathrm{nmol} / \mathrm{L})$ we observed after intake of the single dose Pycnogenol containing $975 \mu \mathrm{g}$ free ferulic acid again appears to be high. After ingestion of $250 \mathrm{mg}$ ferulic acid from breakfast cereals plasma concentrations of $150-210 \mathrm{nmol} / \mathrm{L}$ were described [27]. However, additional ferulic acid might be present in the pine bark extract in conjugated form and it is known to be generated in vivo by methylation of caffeic acid $[6,16]$. The fact that the plasma concentrations of ferulic acid are almost constant between $2 \mathrm{~h}$ and $14 \mathrm{~h}$ favour the notion of additionally generated ferulic acid, e.g. from caffeic acid. The remarkably high steady state concentrations of ferulic acid (about $20 \mathrm{ng} / \mathrm{mL}$ ) after repeated intake of Pycnogenol along with the rather low steady state concentrations of caffeic acid furthermore support the concept of metabolic generation of ferulic acid. The elimination half-live of ferulic acid we calculated (6.87 \pm $3.83 \mathrm{~h}$ ) is completely consistent with the $\mathrm{t}^{1 / 2}$ of $6.35 \pm 2.95$ 
$\mathrm{h}$ reported by Wittemer et al. [6]. In our study we did not detect any free, only conjugated ferulic acid after repeated intake of maritime pine bark extract whereas around $25 \%$ free ferulic acid was found after single ingestion of beer [26].

Taxifolin was detected not before $2 \mathrm{~h}$ after ingestion of the pine bark extract and maximal plasma concentrations were recorded after $8 \mathrm{~h}$. Furthermore, no steady state concentrations of conjugated or free taxifolin were detectable after multiple intake of Pycnogenol. This plasma concentration profile of taxifolin was quite unexpected since free taxifolin is present in the extract at higher concentrations than other polyphenol monomers. To our knowledge, no plasma concentrations of taxifolin have been reported for humans before. We supposed that the compound's late appearance in plasma and the lack of steady state levels is due to metabolic degradation processes. The anaerobic bacterium Clostridium orbiscindens was found in human feces recently [28]. This bacterium has the ability to degrade taxifolin to 3,4-dihydroxyphenylacetic acid and phloroglucin. However, we failed to detect either of these metabolites in the volunteers' plasma samples.

The catechin metabolites $M 1$ ( $\delta$-(3,4-dihydroxy-phenyl)$\gamma$-valerolactone) and M2 ( $\delta$-(3-Methoxy-4-hydroxy-phenyl)- $\gamma$-valerolactone) have been previously found in urine samples after oral intake of maritime pine bark extract [15] and thus we expected their presence in plasma samples as well. However, we only detected the metabolite M1 after intake of a single dose and after repeated ingestion of Pycnogenol. Since $c_{\max }$ concentrations of M1 were only around $4 \mathrm{ng} / \mathrm{mL}(\approx 20 \mathrm{nmol} / \mathrm{L})$ after single and repeated dosing we assume that our analytical method was not sensitive enough to detect M2 (lower limit of quantitation: 50 $\mathrm{ng} / \mathrm{mL}$ ). Consistent with the information that $\mathrm{M} 1$ is generated from catechin units $[15,17]$ we observed at late $t_{\max }$ $10 \mathrm{~h}$ after ingestion of the extract. Peak plasma levels of M1 were observed 5-12 h after ingestion of green tea [29] and earliest appearance of M1 has been recorded after $3 \mathrm{~h}$ after green tea ingestion [30].

Along with the above discussed five known constituents or metabolites of Pycnogenol ten so far unknown compounds were found in the volunteers' plasma samples. These substances are not identical to any other known free polyphenol monomer in the maritime pine bark extract. They may, however, be conjugates of monomers or metabolites of higher procyanidin oligomers. It is also conceivable that a procyanidin dimer is among these unknown compounds. The procyanidin $\mathrm{B} 1$ has been detected in human plasma samples [31] and this procyanidin is a constituent of Pycnogenol as well. The unknown compound $\mathrm{U} 10$ displays a $\mathrm{t}_{\max } 4 \mathrm{~h}$ after ingestion of the extract. Based on this time course it is very likely that $\mathrm{U} 10$ is a constituent rather than a metabolite of Pycnogenol. In contrast, it can be assumed that the compounds U8 and U9 which are detectable only between $8 \mathrm{~h}$ and $10 \mathrm{~h}$ are metabolites which are either rapidly eliminated or further metabolized. Consequently, these are the only compounds besides taxifolin which are not present in the steady states plasma samples of a single volunteer. The compounds U5 and U6 display typical plasma profiles of metabolites as well since they cannot be discovered before $6 \mathrm{~h}$ or $8 \mathrm{~h}$, respectively, after ingestion of Pycnogenol. The unknown compounds U1, U2, U3, U4 and U7 were all readily detectable in plasma after $0.5 \mathrm{~h}$ and all revealed an essentially biphasic plasma concentration profile. Although the individual $t_{\max }$ values vary considerably all substances have one early and one late $t_{\max }$. Multiple $t_{\max }$ values are consistent with either enterohepatic circulation of a compound or with successive metabolic generation of additional substance, e.g. by breakdown of higher procyanidin oligomers.

Regarding the plasma time course of constituents or metabolites of Pycnogenol two observations are remarkable. One is that apparently many constituents are bioavailable after oral ingestion and obviously pronounced metabolism occurs. The other fact is that the concentrations of known compounds both after single and multiple dosing are within the $\mathrm{ng} / \mathrm{mL}$ range translating into nanomolar concentrations. This appears to be very low and reminds of a question brought up by Goldberg et al. [22] whether biologically effective polyphenol concentrations are attainable in humans. We previously elucidated the effects of two Pycnogenol metabolites, M1 and M2, towards inhibition of activity and release of matrix metalloproteinases (MMP) in vitro and in cell culture assays [32]. We found that both metabolites were effective in inhibition of MMP-9 release with $\mathrm{IC}_{50}$ values of $0.5 \mu \mathrm{M}$. In the present study we learned that these concentrations were not detected in the volunteers' plasma samples. Various conclusions are possible; one is that the in vitro experiments are irrelevant because concentrations required for e.g. anti-inflammatory effects are not attained in vivo. Opposing this view is the fact that Pycnogenol has demonstrated in vivo efficacy in various clinical studies $[3,11]$. Another conclusion might be that various substances act synergistically and thus efficacy is seen at lower levels of the individual compound. However, so far there are no proofs for this. A last conclusion we would like to suggest is that we possibly have been looking for the wrong compounds. While most in vitro studies focused on free polyphenolic monomers it has been reported that the conjugates might exert effects as well $[33,34]$. Our present study furthermore indicates that multiple unknown constituents and/or metabolites are present in plasma samples after ingestion of maritime pine bark extract. These might well be responsible for the pharmacodynamic 
effects of Pycnogenol. Our recent results support the suggestion that active principles with significant bioefficacy are present in plasma of human volunteers after ingestion of the extract. Aliquots of plasma samples from the volunteers of the present study were previously assayed for their effects towards cyclooxygenase (COX) activity [35]. The plasma samples after multiple intake of Pycnogenol revealed moderate, but no significant inhibition of COX1 and COX-2. In contrast, plasma samples obtained $0.5 \mathrm{~h}$ after ingestion of the extract significantly inhibited both COX enzymes. We also employed the steady state plasma samples in cell culture assays. Although these plasma samples were diluted 1:1 with cell culture medium they still moderately inhibited NF- $\kappa \mathrm{B}$ activation and significantly inhibited release of MMP-9 from activated human monocytes [36]. Consequently, we now have to identify the unknown compounds detected after Pycnogenol intake and elucidate their anti-inflammatory activities.

\section{Conclusion}

We present the first systematic pharmacokinetic analysis of constituents and metabolites of the standardized maritime pine bark extract (USP quality) after single and repeated intake by human volunteers. Components of the extract were bioavailable and detectable in the plasma of all subjects. Pharmacokinetic parameter calculated for the so far identified compounds were comparable with results from other studies. In addition, for the first time we describe steady state concentrations of catechin, caffeic acid, ferulic acid and M1 ( $\delta$-(3,4-dihydroxy-phenyl)- $\gamma$ valerolactone) and present the first taxifolin plasma concentrations in humans. The detection of ten so far unknown bioavailable constituents and metabolites of Pycnogenol reveal potential for uncovering active compounds with anti-inflammatory bioefficacy.

\section{Competing interests}

This work was supported by a research grant of Horphag Research. They had no role in the collection, analysis and interpretation of data or in the writing of the manuscript.

\section{Authors' contributions}

T.G. carried out all experiments with the plasma samples and the data analysis.

R.S. developed and applied the HPLC method for quantitation of the extract components.

Z.C. recruited the volunteers and organized the study, prepared the technical documentation for blood sampling.

J.M. and K.S. took care of the volunteers and performed blood sampling and processed samples according to the protocol.
A.L. prepared the project and processed blood samples.

Z.D. contributed to planning of the design and execution of the project and wrote the ethic's committee application.

P.H. conceived of and designed the study and wrote the manuscript.

All authors read and approved the final manuscript.

\section{Acknowledgements}

Z.D. was additionally supported by a VEGA grant of the Ministry of Education of Slovak Republic and by Mind \& Health civil association. This funding had no role in the collection, analysis and interpretation of data or in the writing of the manuscript.

\section{References}

I. Gurley BJ, Gardner SF, Hubbard MA, Williams DK, Gentry WB, Carrier J, Khan IA, Edwards DJ, Shah A: In vivo assessment of botanical supplementation on human cytochrome P450 phenotypes: Citrus aurantium, Echinacea purpurea, milk thistle, and saw palmetto. Clin Pharmacol Ther 2004, 76:428-440.

2. Rengelshausen J, Banfield M, Riedel KD, Burhenne J, Weiss J, Thomsen T, Walter-Sack I, Haefeli WE, Mikus G: Opposite effects of short-term and long-term St John's wort intake on voriconazole pharmacokinetics. Clin Pharmacol Ther 2005, 78:25-33.

3. Williamson G, Manach C: Bioavailability and bioefficacy of polyphenols in humans. II. Review of 93 intervention studies. Am J Clin Nutr 2005, 81:243S-255S.

4. Liu JP, Zhang M, Wang WY, Grimsgaard S: Chinese herbal medicines for type 2 diabetes mellitus. Cochrane Database Syst Rev 2004:CD003642.

5. Manach C, Williamson G, Morand C, Scalbert A, Remesy C: Bioavailability and bioefficacy of polyphenols in humans. I. Review of 97 bioavailability studies. Am J Clin Nutr 2005, $81: 230 S-242 S$.

6. Wittemer SM, Ploch M, Windeck T, Muller SC, Drewelow B, Derendorf $\mathrm{H}$, Veit M: Bioavailability and pharmacokinetics of caffeoylquinic acids and flavonoids after oral administration of Artichoke leaf extracts in humans. Phytomedicine 2005, 12:28-38.

7. Loew D, Schrodter A, Schwankl W, Marz RW: Measurement of the bioavailability of aescin-containing extracts. Methods Find Exp Clin Pharmacol 2000, 22:537-542.

8. Schulz HU, Schurer M, Bassler D, Weiser D: Investigation of the bioavailability of hypericin, pseudohypericin, hyperforin and the flavonoids quercetin and isorhamnetin following single and multiple oral dosing of a hypericum extract containing tablet. Arzneimittelforschung 2005, 55:15-22.

9. Vuksan V, Sievenpiper JL: Herbal remedies in the management of diabetes: lessons learned from the study of ginseng. Nutr Metab Cardiovasc Dis 2005, 15:149-160.

10. Maritime Pine Extract. In United States Pharmacopeia Volume 28. Rockville, United States Pharmacopeial Convention, Inc.; 2005:2115-2116.

II. Rohdewald P: A review of the French maritime pine bark extract (Pycnogenol), a herbal medication with a diverse clinical pharmacology. Int J Clin Pharmacol Ther 2002, 40: I58-I68.

12. Belcaro G, Cesarone MR, Errichi BM, Ledda A, Di Renzo A, Stuard S, Dugall M, Pellegrini L, Rohdewald P, Ippolito E, Ricci A, Cacchio M, Ruffini I, Fano F, Hosoi M: Venous ulcers: microcirculatory improvement and faster healing with local use of pycnogenol((r)). Angiology 2005, 56:699-705.

13. Hosseini S, Pishnamazi S, Sadrzadeh SM, Farid F, Farid R, Watson RR: Pycnogenol((R)) in the Management of Asthma. J Med Food 200I, 4:20I-209.

14. Lau BH, Riesen SK, Truong KP, Lau EW, Rohdewald P, Barreta RA: Pycnogenol as an adjunct in the management of childhood asthma. J Asthma 2004, 41:825-832. 
15. Düweler KG, Rohdewald P: Urinary metabolites of French maritime pine bark extract in humans. Pharmazie 2000, 55:364-368.

16. Virgili F, Pagana G, Bourne L, Rimbach G, Natella F, Rice-Evans C, Packer L: Ferulic acid excretion as a marker of consumption of a French maritime pine (Pinus maritima) bark extract. Free Radic Biol Med 2000, 28: I 249-I 256.

17. Das NP: Studies on flavonoid metabolism. Absorption and metabolism of (+)-catechin in man. Biochem Pharmacol 1971, 20:3435-3445

18. Lipinski CA, Lombardo F, Dominy BW, Feeney PJ: Experimental and computational approaches to estimate solubility and permeability in drug discovery and development settings. Adv Drug Deliv Rev 200I, 46:3-26.

19. Donovan JL, Bell JR, Kasim-Karakas S, German JB, Walzem RL, Hansen RJ, Waterhouse AL: Catechin is present as metabolites in human plasma after consumption of red wine. J Nutr 1999, | 29:1662-|668.

20. Bell JR, Donovan JL, Wong R, Waterhouse AL, German JB, Walzem RL, Kasim-Karakas SE: (+)-Catechin in human plasma after ingestion of a single serving of reconstituted red wine. $\mathrm{Am} J$ Clin Nutr 2000, 7I:103-108.

2I. Hackett AM, Griffiths LA, Broillet A, Wermeille M: The metabolism and excretion of (+)-[ I 4C]cyanidanol-3 in man following oral administration. Xenobiotica 1983, 13:279-286.

22. Goldberg DM, Yan J, Soleas GJ: Absorption of three wine-related polyphenols in three different matrices by healthy subjects. Clin Biochem 2003, 36:79-87.

23. Caccetta RA, Croft KD, Beilin LJ, Puddey IB: Ingestion of red wine significantly increases plasma phenolic acid concentrations but does not acutely affect ex vivo lipoprotein oxidizability. Am J Clin Nutr 2000, 71:67-74.

24. Simonetti $P$, Gardana $C$, Pietta P: Caffeic acid as biomarker of red wine intake. Methods Enzymol 200I, 335:122-130.

25. Nardini M, Cirillo E, Natella F, Scaccini C: Absorption of phenolic acids in humans after coffee consumption. J Agric Food Chem 2002, 50:5735-5741.

26. Nardini M, Natella F, Scaccini C, Ghiselli A: Phenolic acids from beer are absorbed and extensively metabolized in humans. J Nutr Biochem 2006, I 7:|4-22.

27. Kern SM, Bennett RN, Mellon FA, Kroon PA, Garcia-Conesa MT: Absorption of hydroxycinnamates in humans after high-bran cereal consumption. J Agric Food Chem 2003, 5 I:6050-6055.

28. Schoefer L, Mohan R, Schwiertz A, Braune A, Blaut M: Anaerobic degradation of flavonoids by Clostridium orbiscindens. Appl Environ Microbiol 2003, 69:5849-5854.

29. Li C, Lee MJ, Sheng S, Meng X, Prabhu S, Winnik B, Huang B, Chung JY, Yan S, Ho CT, Yang CS: Structural identification of two metabolites of catechins and their kinetics in human urine and blood after tea ingestion. Chem Res Toxicol 2000, 13:177-184

30. Lee MJ, Maliakal P, Chen L, Meng X, Bondoc FY, Prabhu S, Lambert G, Mohr S, Yang CS: Pharmacokinetics of tea catechins after ingestion of green tea and (-)-epigallocatechin-3-gallate by humans: formation of different metabolites and individual variability. Cancer Epidemiol Biomarkers Prev 2002, I I: I025-I032.

31. Sano A, Yamakoshi J, Tokutake S, Tobe K, Kubota Y, Kikuchi M: Procyanidin $B I$ is detected in human serum after intake of proanthocyanidin-rich grape seed extract. Biosci Biotechnol Biochem 2003, 67: I|40-II43.

32. Grimm T, Schäfer A, Högger P: Antioxidant activity and inhibition of matrix metalloproteinases by metabolites of maritime pine bark extract (pycnogenol). Free Radic Biol Med 2004, 36:81 I-822.

33. Koga T, Meydani M: Effect of plasma metabolites of (+)-catechin and quercetin on monocyte adhesion to human aortic endothelial cells. Am J Clin Nutr 2001, 73:941-948.

34. Moon $\mathrm{JH}$, Tsushida $\mathrm{T}$, Nakahara $\mathrm{K}$, Terao J: Identification of quercetin 3-O-beta-D-glucuronide as an antioxidative metabolite in rat plasma after oral administration of quercetin. Free Radic Biol Med 200I, 30:1274-I 285.

35. Schäfer A, Chovanova Z, Muchova J, Sumegova K, Liptakova A, Durackova Z, Högger P: Inhibition of COX-I and COX-2 activ ity by plasma of human volunteers after ingestion of French maritime pine bark extract (Pycnogenol). Biomed Pharmacother 2006, 60:5-9.
36. Grimm T, Chovanova Z, Muchova J, Sumegova K, Liptakova A Durackova Z, Högger P: Inhibition of NF-kappaB activation and MMP-9 secretion by plasma of human volunteers after ingestion of maritime pine bark extract (Pycnogenol). I Inflamm (Lond) 2006, 3:I.

\section{Pre-publication history}

The pre-publication history for this paper can be accessed here:

http://www.biomedcentral.com/1472-6904/6/4/prepub
Publish with Biomed Central and every scientist can read your work free of charge

"BioMed Central will be the most significant development for disseminating the results of biomedical research in our lifetime. "

Sir Paul Nurse, Cancer Research UK

Your research papers will be:

- available free of charge to the entire biomedical community

- peer reviewed and published immediately upon acceptance

- cited in PubMed and archived on PubMed Central

- yours - you keep the copyright
BioMedcentral 